\title{
Hodgkin's granuloma complicated by generalized cytomegalic inclusion disease and gastrointestinal moniliasis
}

\author{
MICHAEL S. ROSE \\ From the Erdheim Institute of Pathology, Government Hospital, \\ Tel Hashomer, State of Israel
}

SYNOPSIS A case is described in which Hodgkin's disease was complicated by inclusion disease and gastrointestinal moniliasis. This is one of several cases of malignant disease complicated by uncommon infections.

Episodes of infection fairly commonly complicate Hodgkin's disease, and the relative frequency of viral and mycotic infestations is striking (Aisenberg, 1964). Generalized cytomegalic inclusion disease is uncommonly seen in adults and is almost always secondary to a debilitating disease (Symmers, 1960).

\section{CASE REPORT}

M.Y. was a 74-year-old widow of European origin who presented in November 1963 with an extensive violet zone in the skin of the right lower abdomen and firm enlarged lymph nodes in both inguinal regions. Biopsies taken from the skin and lymph nodes showed appearances consistent with Hodgkin's disease. At this stage her general condition was satisfactory. She was treated with nitrogen mustard and steroids. During the following months she developed generalized, painless lymph-node enlargement and an extensive ulcer on the adductor surface of the right thigh. She was treated with vincoleucoblastine and antibiotics but died with fulminant sepsis in October 1964.

A post-mortem examination was performed 15 hours after death and we found enlargement of all lymph-node groups and multiple cutaneous nodules on the chest and abdomen. The spleen was moderately enlarged and homogeneous on section. Section through the liver showed many tiny pale spots throughout the organ. In the gastrointestinal tract there were many discrete mucosal ulcers.

Microscopic examination showed that normal architecture of the lymph nodes had been replaced by pleiomorphic cellular constituents of Hodgkin's disease. Within the lung alveoli were cells of up to $35 \mu$ in diameter, with nuclei about $20 \mu$ in diameter, which were round and regular with centrally situated, variously

Received for publication 16 October 1965.

'Present address: Department of Haematology, Wright-Fleming Institute of Microbiology, St. Mary's Hospital, London, W.2.

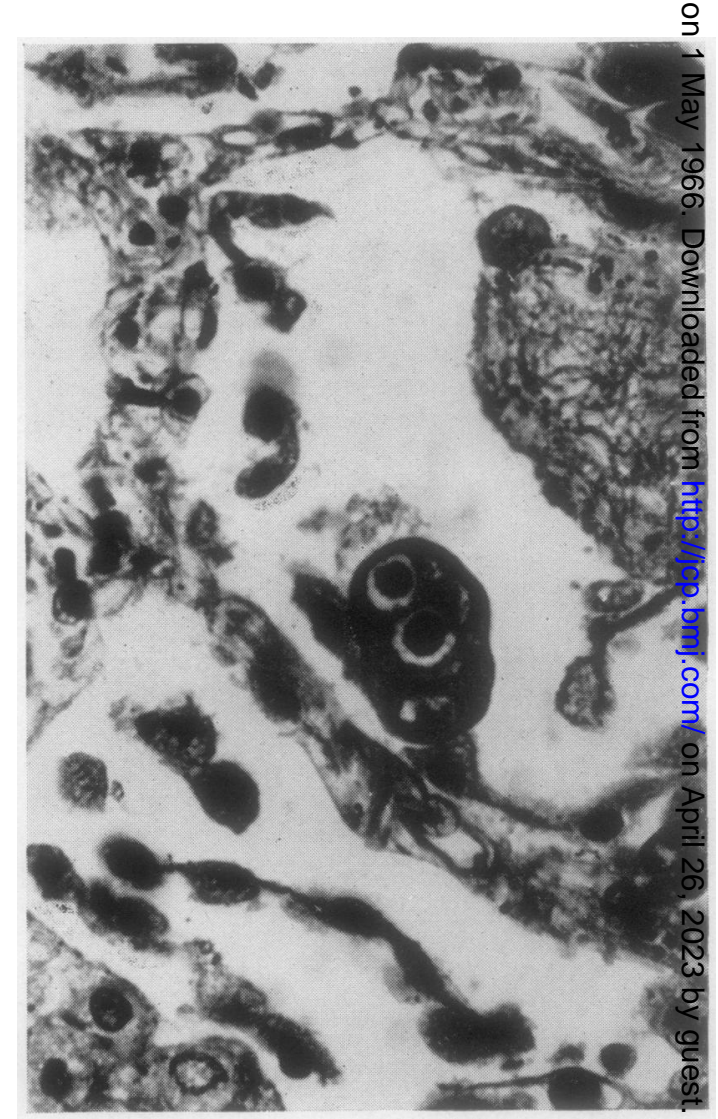

FIG. 1. Lung alveoli showing detail of multinuclegte megalocyte with characteristic homogeneous, deegly stained, intranuclear inclusions surrounded by peripheral halo. There are also densely staining, punctate cytoplas कृic zones. Haematoxylin and eosin stain $(\times 650)$. 
eosinophilic, basophilic, or amphophilic, homogeneous inclusions of about $15 \mu$ in diameter, surrounded by a clear halo (Fig. 1). In some of these cells the nuclei were eccentric and there were small, discrete, basophilic spots in the cytoplasm. In some sections there were up to 12 such cells per high-power field. There were also a number of binucleated and multinucleate forms. The nuclear inclusions were Feulgen-positive. Inflammatory cells were notably absent. The splenic white pulp was extremely atrophic and a number of cells were identified in the red pulp in which there were large nuclear inclusions. Similar cells were found lining thyroid acini, in the adrenal cortex, anterior pituitary, renal tubules, liver parenchyma, and bone marrow. Sections from the stomach and small intestine showed a number of mucosal ulcers with overlying necrotic debris within which mycelia of Candida albicans were dispersed.

\section{DISCUSSION}

During the past six months we have encountered in this institute a number of uncommon infections complicating lympho-reticular malignancies, including the present case, cases of mucor mycosis, aspergillosis, nocardiosis, cryptococcosis, and pneumocystis carinii infection.

The terminal succumbing of the patient to generalized cytomegalic inclusion disease and moniliasis may be attributed to her lowered resistance. The splenic hypoplasia was evidence of the failure of lymphoid tissues.

The immunological incompetence known occasionally to complicate Hodgkin's disease may be inherent in the disease or induced by the treatment. Known manifestations include conversion of Mantoux reactivity from positive to negative (Parker, Jackson, Fitzhugh, and Spies, 1932), delayed homograft rejection (Kelly, Lamb, Good, and Varco, 1958), or failure to induce a delayed hypersensitivity response with standard chemical excitants such as dinitrochlorobenzene (Aisenberg, 1962). Suggested causes of this immunological incompetence include involvement of a major portion of the lymphoid tissue by Hodgkin's disease; suppression of the delayed-type hypersensitivity response by the systemic effects of a localized Hodgkin's granuloma, similar in nature to runt disease (Kaplan and Smithers, 1959); suppression of immunological function by the therapy for Hodgkin's disease. The treatment which our patient received included antibiotics, radiomimetic drugs, antimetabolites, and steroids. These probably contributed to the development of a terminal anergic state.

It is a pleasure to acknowledge the help and advice given to me by the staff of the Pathology Department, Tel Hashomer Hospital, in the preparation of this report.

\section{REFERENCES}

Aisenberg, A. C. (1962). J. clin. Invest., 41, 1964.

- (1964). Medicine (Baltimore), 43, 189.

Kaplan, H. S., and Smithers, D. W. (1959). Lancet, 2, 1.

Kelly, W. D., Lamb, D. L., Good, R. A., and Varco, R. L. (1958). Surg. Gynec. Obstet., 107, 565.

Parker, F., Jr., Jackson, H., Jr., Fitzhugh, G., and Spies, T. D. (1932). J. Immunol., 22, 277.

Symmers, W. St C. (1960). J. clin. Path., 13, 1. 